\title{
PERFORMANCE ANALYSIS OF NETWORK PRODUCTION SYSTEMS BY ANP APPROACH ${ }^{1}$
}

\author{
Petr Fiala, Josef Jablonský \\ Department of Econometrics, University of Economics, \\ W. Churchill Sq. 4, 13067 Prague 3, The Czech Republic, \\ pfiala@vse.cz,jablon@vse.cz
}

Keywords: network production systems, ANP, performance pyramid

Summary: The paper presents a using of ANP approach to study and to measure performance of network production systems. Network production systems can be shown as a set of business units interconnected by information, physical and financial flows from initial suppliers to ultimate customers. The network production system is responsible for global performance whereas each business unit is responsible for local performance. The ANP approach is used for the performance pyramid managerial concept by local performance measuring of business units and to compare the global performance of business units also.

\section{Network production systems}

Network productions systems are focused on transformation of inputs into outputs. The management determines how best to utilize the available inputs of labor, capital, natural resources, materials, technology, energy and information to achieve the objectives. The objectives are often conflicting. The production system can be shown as interrelated sets of resources, products, processes, tasks, plans and events.

A network production system is defined as a network of organizations that are involved, through linkages, in the different processes and activities that produce value in the form of products and services in the hands of the ultimate customer. In our model we assume a structure of network production systems with sets of potential suppliers, producers, distributors, customers etc. The sets are interconnected by information, physical and financial flows.

In the network production systems independent partners are closely cooperating with each other. Information exchange is very important issue for coordinating actions of units. The expected result is a mutually beneficial, win-win partnership that creates a synergistic network in which the entire network is more effective than the sum of its individual parts. Partnership leads to increased information flows, reduced uncertainty, and a more profitable network.

\section{Performance Pyramid}

Performance models estimate the measures of system performance for a given set of decisions and system parameters. Performance analysis of production systems helps to understand the behavior of these systems and to provide guidelines to improve their performance. The network production system is responsible for global performance whereas each unit is responsible for local performance.

\footnotetext{
1 The paper is supported by the Grant Agency of Czech Republic - grants no. 402/01/0771 and 402/01/0133.
} 
Different perspectives must be considered in contrast to a traditional single focus on financial performance. The performance pyramid represents a comprehensive, fully integrated performance system that captures multiple perspectives as internal, financial, customer and innovation. Each side of the pyramid represents a perspective as a hierarchical structure of success factors, managerial measures and process drivers. Not only are measures and process drivers linked to each side of pyramid, but linkages also exist to other sides of the pyramid as impact of process drivers on more than one key perspective.

\section{Analytic Network Process}

The Analytic Network Process (ANP) is the method that makes it possible to deal systematically with all kinds of dependence and feedback in the performance system. The well-known AHP theory is a special case of the Analytic Network Process that can be very useful for incorporating linkages in the performance system.

The ANP approach is used for the performance pyramid managerial concept by local performance measuring of business units and to compare the global performance of business units also. The structure of the ANP model is described by clusters of elements connected by their dependence on one another. A cluster groups elements (success factors, managerial measures, process drivers, business units) that share a set of attributes. At least one element in each of these clusters is connected to some element in another cluster. We take into account connections in the performance pyramid and connections in network systems. These connections indicate the flow of influence between the elements. Paired comparisons are needed for all the connections in the performance model. Paired comparisons are inputs for computing a global performance of network production systems.

\section{Conclusion}

The analysis and design of the network production systems has been an active area of research. Performance models help to understand the behaviour of these systems and to provide guidelines to improve their performance. The network production system is responsible for global performance whereas each unit is responsible for local performance. The ANP approach seems to be an appropriate method for performance measuring of network production systems. We are developing a simple software system for this approach. The system is building as an add-in application within MS Excel environment using Visual Basic for Application language. An illustrative example is added. The results given by our system and by alpha version of the ANP software developed by Creative Decisions Foundation (CDF) are compared and discussed. The alpha version of the ANP software can be downloaded for testing from the CDF www page.

\section{References}

Fiala, P., Kukal, J.(2000), "Modeling of cooperation in network production systems", APORS 2000,Singapore.

CDF (Creative Decisions Foundation) www page (2000) - www.creativedecisions.net.

Rouse, P., Puterill, M. and Ryan, D. (1997) “Towards a General Managerial Framework for Performance Measurement: A Comprehensive Highway Maintenance Application", Journal of Productivity Analysis, 8, 127-149.

Saaty, T.L. (1990) The Analytic Hierarchy Process, Pittsburgh, RWS Publications.

Saaty, T.L. (1996) Decision making with Dependence and Feedback: The Analytic Network Process, Pittsburgh, RWS Publications.

Saaty, T.L. (1999) "Fundamentals of the Analytic Network Process", Proceedings of the $5^{\text {th }}$ International Conference on the Analytic Hierarchy Process, Kobe, pp. 20-33. 